\title{
Aqueous dispersions of silver nanoparticles in polyelectrolyte solutions
}

\author{
DAN DONESCU ${ }^{\mathrm{a}}$, RALUCA SOMOGHI ${ }^{\mathrm{a}, *}$, MARIUS GHIUREA ${ }^{\mathrm{a}}$, RALUCA IANCHIS ${ }^{\mathrm{a}}$, \\ CRISTIAN PETCU ${ }^{\mathrm{a}}$, STEFANIA GAVRILIU ${ }^{\mathrm{b}}$, MAGDALENA LUNGU ${ }^{\mathrm{b}}$, \\ CLAUDIA GROZA $^{\mathrm{b}}$, CARMEN R IONESCU ${ }^{\mathrm{c}}$ and CARMEN PANZARU ${ }^{\mathrm{c}}$

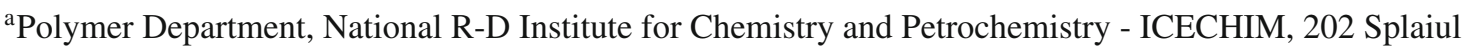 \\ Independentei, 060021, Bucharest, Romania \\ ${ }^{b}$ National R-D Institute for Electrical Engineering ICPE - CA, 313 Splaiul Unirii, 030138, Bucharest, Romania \\ 'University of Medicine and Pharmacy 'Gr. T. Popa', 16 Universitatii Street, 700115, Iassy, Romania \\ e-mail: ralucasomoghi@yahoo.com
}

MS received 24 January 2012; revised 21 May 2012; accepted 29 June 2012

\begin{abstract}
In this report, we present the versatile and effective technique, using environmental friendly reductant glucose, to prepare stable silver nanodispersions by reduction of $\mathrm{Ag}^{+}$ions. Alternant copolymers of maleic anhydride with vinyl acetate and styrene sulphonate sodium acid salt polyelectrolytes were synthesized in aqueous solution and used as stabilizers. The formation of nano silver particles was confirmed by UV-Vis spectrophotometry and TEM measurements. Dynamic Light Scattering (DLS) measurements were needed to study how the reagents and their concentrations influence particle size. SEM images show the nanostructure of the hybrid films and indicate a strong interaction between the polyelectrolyte and the silver NPs. Moreover, the silver NPs could be stored for one year without observation of aggregates or sedimentation. The final solid products obtained after evaporating to dryness can be used to produce stable dispersions upon mixing with water. Few of the final products were found to exhibit a high antibacterial and antifungal activity.
\end{abstract}

Keywords. Silver nanodispersions; polyelectrolytes; antibacterial and antifungal activity.

\section{Introduction}

Hybrid materials based on polymer-metallic nanoparticles have been intensively studied due to their capacity to provide potential applications in biotechnology, optics, electronics, catalysis, etc. ${ }^{1}$ Silver nanoparticles hybrids the quality of life by decreasing contamination from bacteria and moulds. ${ }^{2-6}$

It is desirable to produce silver polymer nanocomposites as sterilization agent have dispersions in water or in non-toxic solvents. In order to obtain sterilization agents based on silver polymer nanocomposites, aqueous or non-toxic solvents dispersions must be used. Silver nanoparticles are synthesis products obtained from the reaction between salts, such as $\mathrm{AgNO}_{3}$, and reducing agents, as discussed elsewhere, such as hydrazine, ${ }^{3,7}$ sodium borohydride $\left(\mathrm{NaBH}_{4}\right),{ }^{4,6,8-11}$ sodium citrate, ${ }^{5}$ sodium acrylate, ${ }^{12}$ sodium polyacrylate, ${ }^{12}$ polyallylamine, ${ }^{13}$ etc. The reducing agents and their reaction products generate environmental problems as a result of metal nanoparticles contamination.

*For correspondence
An earlier study ${ }^{14}$ reported the synthesis of silver NPs by $\mathrm{AgNO}_{3}$ reduction with $\mathrm{NaBH}_{4}$ in the presence of two polyelectrolytes: (i) the sodium salts of maleic anhydride-vinyl acetate copolymer (VAc-MA) and (ii) the sodium salts of maleic anhydride-styrene sulphonic acid copolymer ( $\left.\mathrm{StSO}_{3} \mathrm{Na}-\mathrm{MA}\right)$. In order to avoid the contamination of silver NPs with the oxidation byproducts of $\mathrm{NaBH}_{4}$, we used glucose as a reduction agent, because it is non-toxic, environmentally friendly and efficient as a reducing reagent. ${ }^{15}$

Our work was focused on the synthesis of nanocomposites from aqueous polyelectrolytes with silver NPs prepared by reduction of $\mathrm{AgNO}_{3}$ with glucose and stabilized by VAc-MA and $\mathrm{StSO}_{3} \mathrm{Na}-\mathrm{MA}$ copolymers.

Size distribution by intensity and the zeta potential values of silver nanoparticle dispersions depend on the nature and the concentration of the reagents. Additionally, we observed that synthesis conditions can modify the morphology and properties of the final films, as well as their sterilization capacity.

It is well-known that $\mathrm{Ag}$ ions and Ag-based compounds have antimicrobial effects. However, in order to use $\mathrm{Ag}$ in various fields against microorganisms, it is essential that preparation methods be cost effective and the mechanism of the antimicrobial 
effect to be known. To evaluate the antimicrobial and antifungal effects against various microorganisms, we used Aspergillus niger, Aspergillus fumigatus, Aspergillus flavus, Aspergillus terreus, Chaetomium globosum, Myrothecium verrucaria, Paecilomyces varioti, Penicillium glaucum, Penicillium cyclopium, Stachybotris atra, Trichoderma viride, Scopulariopsis brevicaulis and, for both Gram positive and negative bacteria: Staphiloccocus aureus, Escherichia coli, Pseudomonas aeruginosa, Klebsiella pneumoniae, Enterobacter species (spp), and Acinetobacter baumannii. Other researchers have evaluated the antimicrobial effects against yeast, E. coli and $S$. aureus ${ }^{16,17}$ showing that $\mathrm{Ag}$ nanoparticles exhibit antimicrobial activity against yeast and $E$. coli. In contrast, the inhibitory effect of $\mathrm{Ag}$ nanoparticles was mild in $S$. aureus as compared with other microorganisms; these results suggest that the antimicrobial effects of $\mathrm{Ag}$ nanoparticles may be associated with characteristics of certain bacterial species.

\section{Experimental}

\subsection{Materials}

Vinyl acetate (VAc) and acetone (Chimopar) were purified by distilation. Maleic anhydride (MA) (Fluka) was purified by sublimation. Azoisobutyronitrile (AIBN) (Riedel de Häen) was purified by re-crystallization from methanol. Poly (4-styrenesulphonic acid-comaleic anhydride) sodium salt, $\mathrm{StSO}_{3} \mathrm{Na}-\mathrm{MA}$ (Aldrich), silver nitrate, $\mathrm{AgNO}_{3}$ (Fluka) and glucose (Fluka) were used as received.

\subsection{Syntheses of the copolymers-silver nanoparticles}

For silver polymer nanocomposite preparation, two copolymers were employed: VAc-MA (a 'home made' copolymer) and $\mathrm{StSO}_{3} \mathrm{Na}-\mathrm{MA}$ (a commercially available copolymer). VAc-MA copolymer was prepared in acetone, in the presence of AIBN, as described previously. ${ }^{18}$ The resulting copolymer was hydrolysed and neutralized using aqueous $\mathrm{NaOH}$, and then the acetone was removed by distillation. The resulting mixture was diluted with water to the desired concentrations: $10 \%$, $1 \%$ and $0.1 \%$ wt.

Poly (4-styrenesulphonic acid-co-maleic anhydride) sodium salt $\left(\mathrm{StSO}_{3} \mathrm{Na}-\mathrm{MA}\right)$ was diluted in distilled water to the desired concentrations: $10 \%, 1 \%$ and $0.1 \%$ wt.

A typical silver polymer nanocomposite preparation is described as follows (table 1, scheme 1): to $60 \mathrm{~g}$ of diluted polyelectrolyte solution $(10 \%, 1 \%$ and $0.1 \%)$ was added and a given amount of $\mathrm{AgNO}_{3}$ (table 1)
Table 1. The number of the samples and the amounts of polyelectrolytes and $\mathrm{AgNO}_{3}$ used in synthesis.

\begin{tabular}{lcccc}
\hline & & & \multicolumn{2}{c}{ Polyelectrolyte (g) } \\
\cline { 4 - 5 } $\begin{array}{l}\text { Sample } \\
\text { no. }\end{array}$ & $\begin{array}{c}\mathrm{AgNO}_{3} \\
(\mathrm{~g})\end{array}$ & $\begin{array}{c}\text { Glucose } \\
(\mathrm{g})\end{array}$ & $\begin{array}{c}\text { Copolymer } \\
\text { VAc-MA }\end{array}$ & $\begin{array}{c}\text { Copolymer } \\
\mathrm{StSO}_{3} \text { Na-MA }\end{array}$ \\
\hline 1 & 0.0584 & 0.00625 & 6 & - \\
2 & & & 0.6 & - \\
3 & & & 0.06 & - \\
4 & 0.1168 & 0.125 & 6 & - \\
5 & & & 0.6 & - \\
6 & & & 0.06 & - \\
7 & 0.2336 & 0.25 & 6 & - \\
8 & & & 0.6 & - \\
9 & & & 0.06 & - \\
10 & 0.5840 & 0.625 & 6 & - \\
11 & & & 0.6 & - \\
12 & & & 0.06 & - \\
13 & 0.0584 & 0.00625 & - & 6 \\
14 & & & - & 0.6 \\
15 & & & - & 0.06 \\
16 & 0.1168 & 0.125 & - & 6 \\
17 & & & - & 0.6 \\
18 & & & - & 0.06 \\
19 & 0.2336 & 0.25 & - & 6 \\
20 & & & - & 0.6 \\
21 & & & - & 0.06 \\
22 & 0.5840 & 0.625 & - & 6 \\
23 & & & - & 0.6 \\
24 & & & - & 0.06 \\
\hline
\end{tabular}

dissolved in $10 \mathrm{~mL}$ of water at room temperature. After 25 min of stirring, a given stoechiometric amount of glucose (table 1), dissolved in $10 \mathrm{~mL}$ of water was added (scheme 2).

The mixture was heated with stirring for $4 \mathrm{~h}$ under stirring at $90^{\circ} \mathrm{C}$. The final solution was brown, indicating the formation of silver NPs. Part of the mixture was cooled and dried in an open air, redundant part was kept in sealed glass vessels for further analyses.

\subsection{Analyses}

The average size of the silver NPs in aqueous medium and the zeta potential were measured with a Zetasizer Nano ZS (Malvern International Ltd.) instrument. The samples were diluted in distilled water $(0,1 \mathrm{~mL} / 25 \mathrm{~mL})$ and ultrasonicated in an ultrasonic bath before measurements.

The $\mathrm{pH}$ values were measured using a $3540 \mathrm{pH}$ and Conductivity Meter (Jenway) instrument.

Fourier Transform Infra Red (FTIR) spectroscopy was performed on a Bruker 37 spectrophotometer, having a Golden Gate ATR unit. 


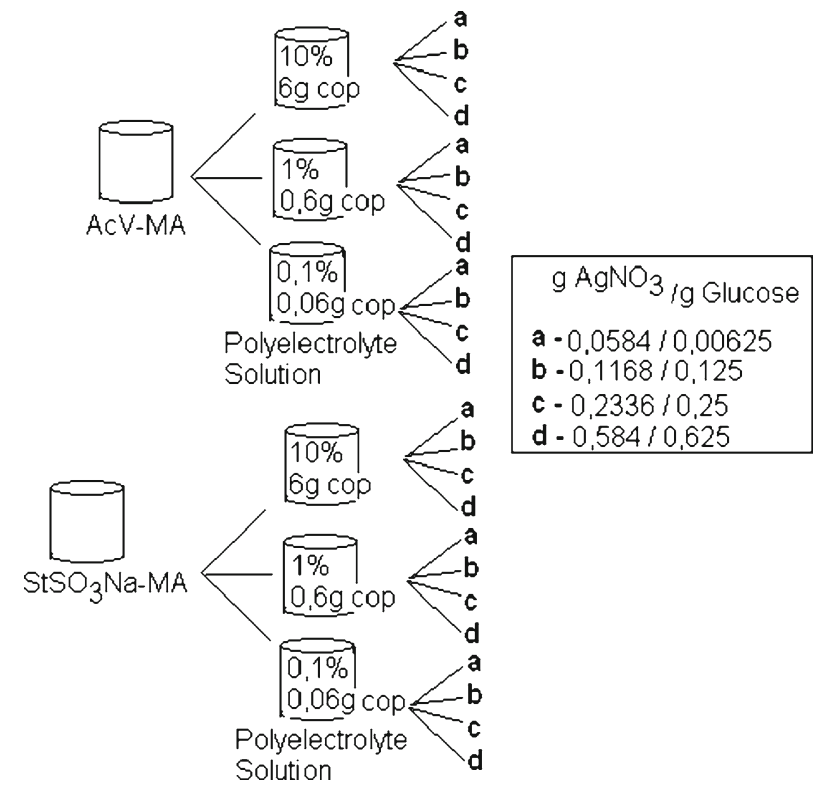

Scheme 1. Compositions used for silver NPs preparation.

The UV-Vis absorption spectra were recorded using a Nicolet 500 spectrometer. For these measurements, samples were diluted in distilled water $(0,1 \mathrm{~mL} / 25 \mathrm{~mL})$ and measured in quartz cells.

Thermo gravimetrically analyses (TGA) were performed using a DuPont 2000 instrument at $20^{\circ} \mathrm{C} / \mathrm{min}$ heating rate, in air.

In order to disperse the agglomerated nanoparticles diluted samples were used. TEM images of the silver NPs were recorded using a Philips CM 100 instrument.

SEM images were recorded using a FEI Quanta 200 instrument. The samples were deposited on $\mathrm{Al}$ stubs with 10 times dilution as needed.

The antifungal properties were evaluated using the antibiograms method, according to IEC 60068-2-10 06/01/2005 'Environmental testing; Part 2-10: Tests;
Test J and guidance: Mould growth-Edition 6'. In summary, $10 \mathrm{~mm}$ diameter round filter paper was immersed into the test sample, added onto a medium of CzapekDox with saccharose, and inoculated by spraying with a suspension of moulds prepared in mineral oil solution. The fungal growth was monitored after 3, 7, 14 and 28 days from the inoculation.

The antibacterial characteristics were evaluated by determining the minimal inhibitory concentration using the dilution technique in agar against a large spectrum of strains including both Gram positive bacteria and Gram negative bacteria: Staphiloccocus aureus, Escherichia coli, Pseudomonas aeruginosa, Klebsiella pneumoniae, Enterobacter spp, and Acinetobacter baumannii. Standard inoculums were seeded according to the scheme recommended by Ericsson and Sherris. The minimal inhibitory concentration was evaluated after an incubation of $18-24 \mathrm{~h}$ in comparison with a reference sample. The inoculums were obtained starting from the basic $0.5 \mathrm{Mc}$ Farland Standard, which contains approximately $1 \times 10^{7}$ to $1 \times 10^{8} \mathrm{CFU} / \mathrm{mL}$, and ten-fold dilutions were performed to a final inoculation of $1 \times 10^{5}$ $\mathrm{CFU} / \mathrm{mL} \cdot{ }^{19-21}$

\section{Results and discussions}

This study employs three different concentrations of polyelectrolyte and four concentrations of glucose and $\mathrm{AgNO}_{3}$. After three months, the samples were analysed in order to determine dispersion stability. Some of the samples stabilized by VAc-MA and by $\mathrm{StSO}_{3} \mathrm{Na}-$ MA precipitated after 3 months. The samples synthesized with $\mathrm{StSO}_{3} \mathrm{Na}-\mathrm{MA}$ have a better stability than the samples with VAc-MA. The lowest concentration of both polyelectrolytes forms unstable dispersions. Contrarily to $\mathrm{NaBH}_{4}$, the use of glucose as a reduction

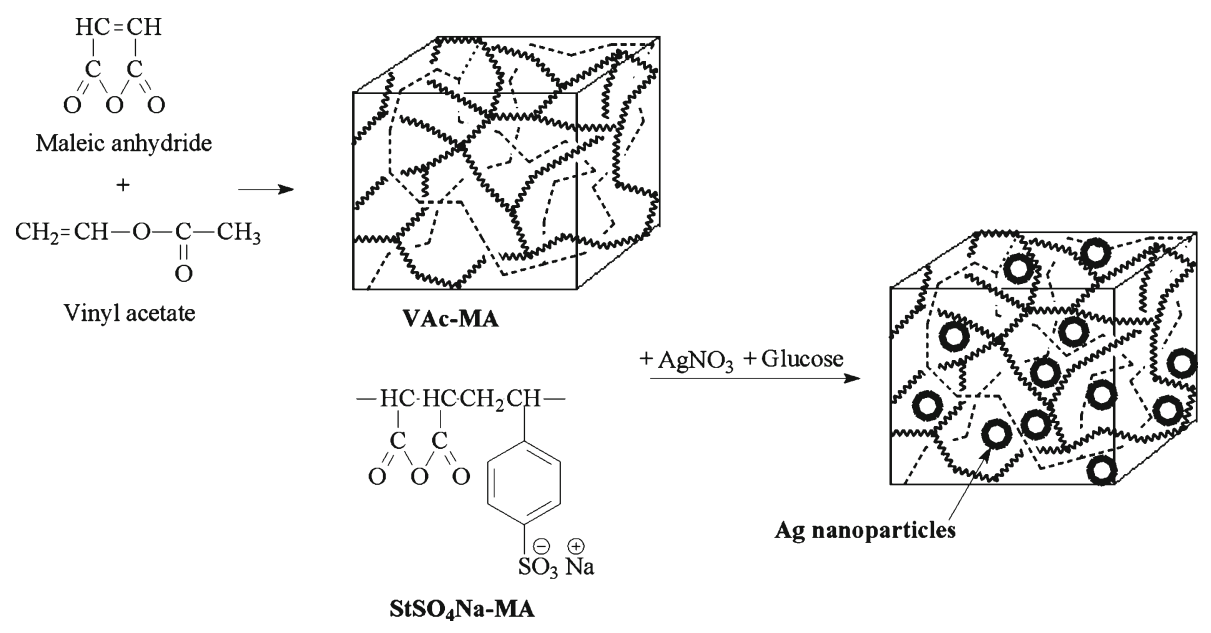

Scheme 2. Schematic illustration depicting the silver NPs hybrids synthesis. 
agent decreases the stability of the final solutions at low polyelectrolytes concentrations. ${ }^{14}$

\subsection{Size measurements}

The average sizes of silver NPs measured by dynamic light scattering are presented in figure 1. For the samples with a smaller content of VAc-MA copolymer $(0.06 \mathrm{~g})$ (figure 1a), the average size of silver NPs increases with increase in $\mathrm{AgNO}_{3}$ content. However, at higher concentrations of polyelectrolyte $(6 \mathrm{~g})$, the average size of silver NPs decreases with increase in $\mathrm{AgNO}_{3}$ content.

The increase of the NPs size for samples with lower amounts $(0,06$ and $0,6 \mathrm{~g})$ of VAc-MA copolymer can be explained by the weaker acidity of the carboxyl groups, and also by the acetate groups which can ensure a weak hydrophobic association in water.
Comparing with the samples prepared with the copolymer VAc-MA (figure 1a), the samples prepared with lower concentration of $\mathrm{StSO}_{3} \mathrm{Na}-\mathrm{MA}$ (figure $1 \mathrm{~b}$ ) exhibited an opposite behaviour: the size of the silver NPs decreased with the increase of the $\mathrm{AgNO}_{3}$ content. This different behaviour was due to the presence of the sulphonic groups, which prevent the particles aggregation. The phenomenon was also observed for the higher concentrations of $\mathrm{StSO}_{3} \mathrm{Na}-\mathrm{MA}$ copolymer (figure $1 \mathrm{~b}$ ).

A similar behaviour was noticed by the Matijevic's group that used the sodium salt of the sulphonated naphthalene formaldehyde condensate as stabilizer. ${ }^{22}$ The interaction between sulphonic groups with $\mathrm{AgNO}_{3}$ forms complexes that can behave as protective species for the metallic particles as in the study of the Matijevic et al.

For low concentrations of $\mathrm{AgNO}_{3}$, complex formation is reduced and as a consequence, the system
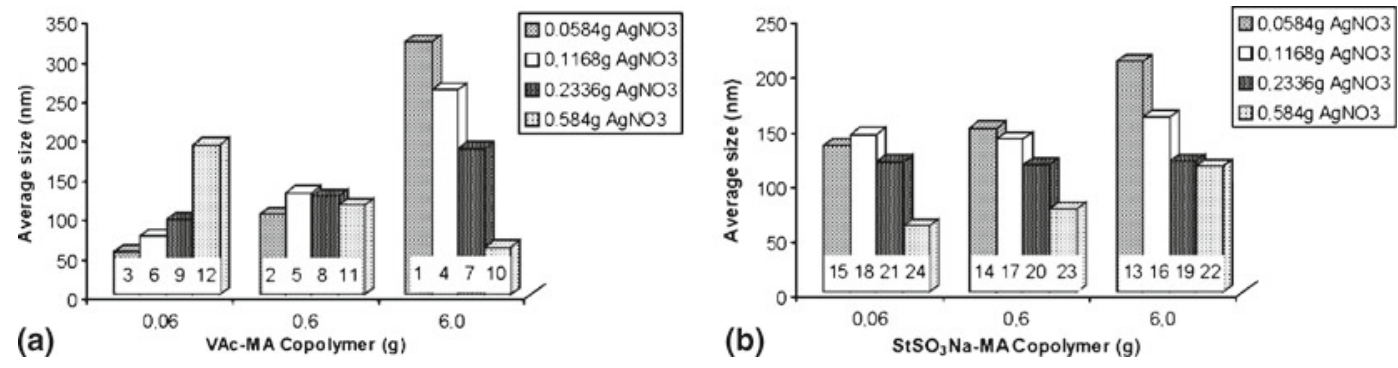

Figure 1. Mean average size of silver NPs depending on the nature and the amount of the reactants: (a) VAc-MA copolymer and (b) $\mathrm{StSO}_{3} \mathrm{Na}-\mathrm{MA}$ copolymer.

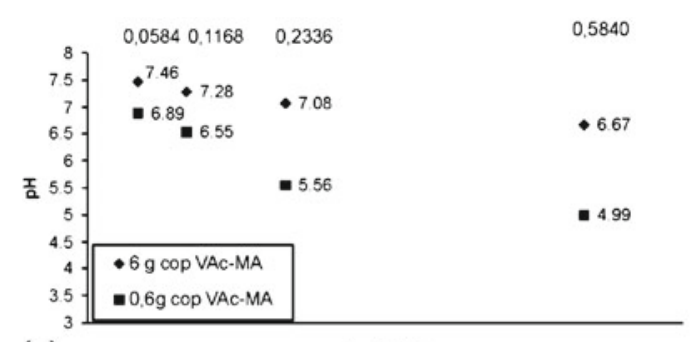

(a)

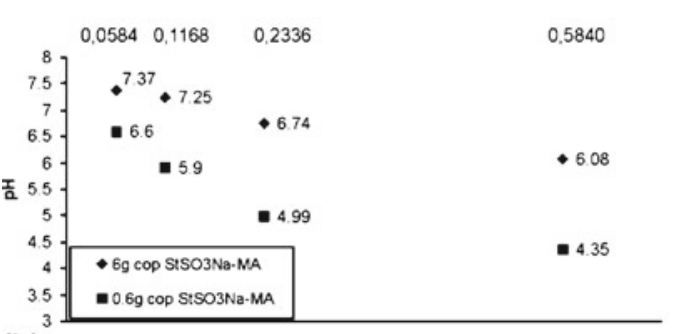

(b)

$\mathrm{AgNO}_{3}(g)$

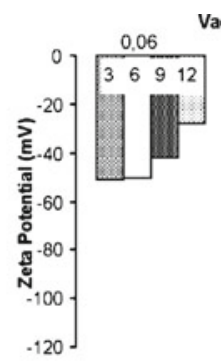

Vac-Ma Copolymer (g)
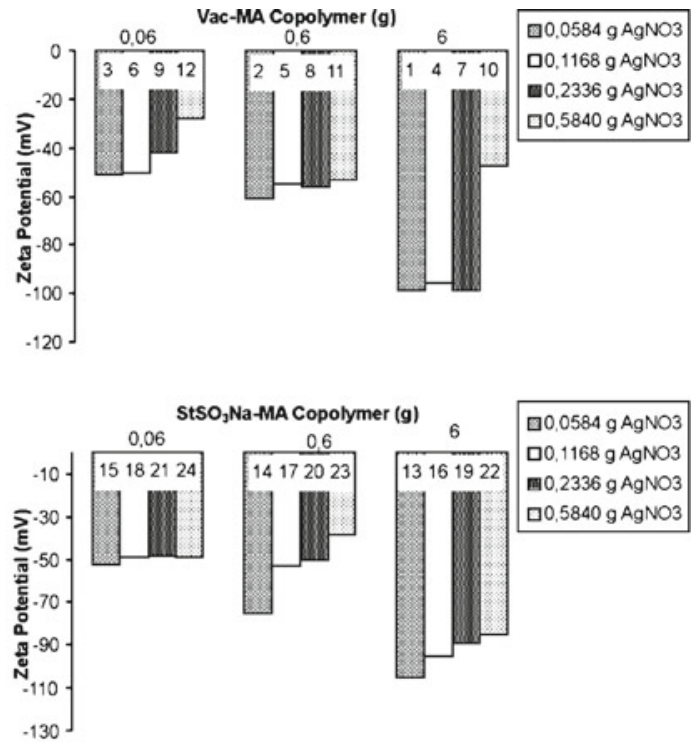

Figure 2. $\mathrm{pH}$ and zeta potential variations of silver NPs dispersions obtained in the presence of (a) VAc-MA and (b) $\mathrm{StSO}_{3} \mathrm{Na}-\mathrm{MA}$ copolymers. 
contains lower amounts of protective species, allowing the newly obtained nanoparticles to agglomerate. This explains why the decrease of the average diameter with the increase of the $\mathrm{AgNO} 3$ content is not so obvious. For the higher concentration of $\mathrm{AgNO}_{3}$ the decrease of the particle size is more pronounced due to the formation of the complexes.

The release of the silver ions increases with the hybrid particles specific surface. As a consequence, we focused on synthesizing stable nanometer sized silver NPs. If the final system is stable, the use of the silver NPs on a large period of time is possible.

\subsection{Zeta potential and $\mathrm{pH}$ measurements}

The mechanism proposed by Matijevic and co-workers ${ }^{22}$ is also sustained by the results obtained by zeta poten- tial measurements. Figure 2 presents the variations of $\mathrm{pH}$ and zeta potential values, measured immediately after synthesis of the silver NPs dispersions. In general, the absolute values of zeta potential decrease with increase of the $\mathrm{AgNO}_{3}$ concentrations, the inorganic phase of the hybrids. The complex formed between $\mathrm{Ag}^{0}$ and ionic groups lowers the ionic load of the polyelectrolyte - silver NPs. The complex has a lower hydrophilicity and a higher capacity to interact with the silver surface, which provides a higher stabilization.

Similar results were noticed for emulsion polymerization of monomers with different polarities. ${ }^{23}$ Polar copolymers have the capacity to interact with water, which increase the quantity of bound-water, contrarily to low polar copolymers. This phenomenon and the hydrophobic interactions between polymer and stabilizer ${ }^{24}$
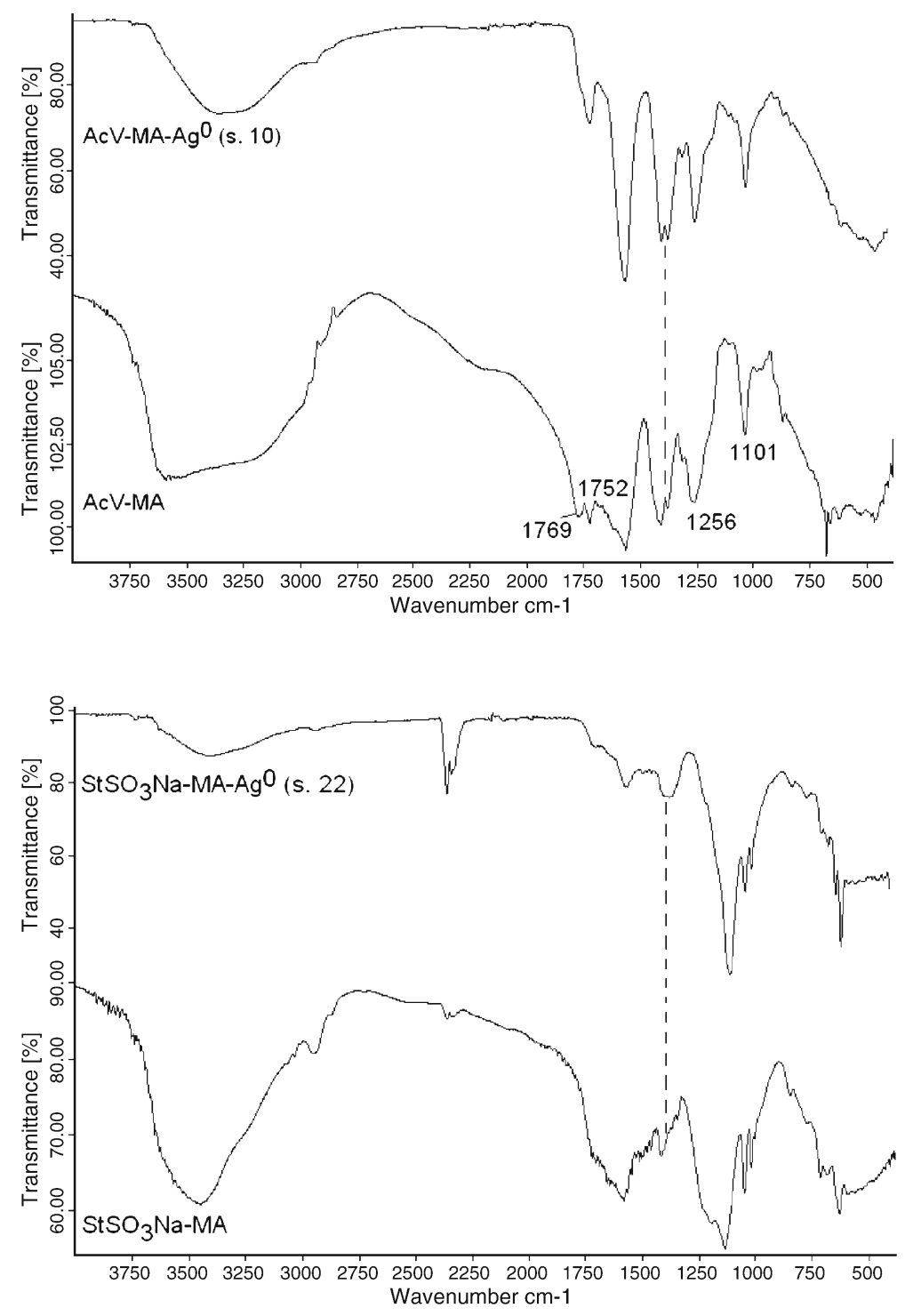

Figure 3. FT-IR spectra of samples (10) with VAc-MA and (22) with $\mathrm{StSO}_{3} \mathrm{Na}-\mathrm{MA}$ and maximum amount of glucose and $\mathrm{AgNO}_{3}$. 
lead to small particles of low polar polymer, stable in water.

The $\mathrm{pH}$ can be correlative with the zeta potential of the final dispersions. ${ }^{22}$ Zeta potentials that are less negative are associated with lower pH's (figure 2). Silver NPs precipitation occurs with release of nitric acid from $\mathrm{AgNO}_{3}$. This also leads to a $\mathrm{pH}$ decrease. Previous work ${ }^{14}$ has shown that another reducing agent $\left(\mathrm{NaBH}_{4}\right)$ act quite opposite as glucose, leading to a $\mathrm{pH}$ increase.

\subsection{FTIR spectra}

The FTIR spectra of samples 10 and 22, containing $6 \mathrm{~g}$ of copolymer, VAc-MA and respective $\mathrm{StSO}_{3} \mathrm{Na}-$ MA with maximum quantities of glucose and $\mathrm{AgNO}_{3}$, compared with the initial copolymers, are presented in figure $3 a$ and $b$.

The AcV-MA copolymer formation can be evidenced by FTIR spectroscopy. The spectra of AcV-MA exhibits characteristic peaks at $1764 \mathrm{~cm}^{-1}(\mathrm{C}=\mathrm{O}$ symmetric stretching band of anhydride groups), $1752 \mathrm{~cm}^{-1}(\mathrm{C}=\mathrm{O}$ symmetric stretching band of $\mathrm{AcV}), 1256 \mathrm{~cm}^{-1}$ (C-O$\mathrm{C}$ stretching band of MAn) and $1101 \mathrm{~cm}^{-1}\left(\mathrm{COCH}_{3}\right.$ streching band of VAc). ${ }^{25}$

In previous studies the bands at 1390 and $1450 \mathrm{~cm}^{-1}$ are attributed to $\mathrm{NO}^{3-}$ ions. ${ }^{26}$ In this case the absence of $\mathrm{AgNO}_{3}$ band at 1390 and $1450 \mathrm{~cm}^{-1}$, noticed for the spectra of both dispersions with Ag particles confirms the reduction of $\mathrm{AgNO}_{3}$ to $\mathrm{Ag}^{0} .{ }^{19}$ The reduction of $\mathrm{Ag}^{+}$to $\mathrm{Ag}^{0}$ can take place by interaction with the surroundings dispersions.

\subsection{TGA analyses}

The interactions between nanoparticles and polyelectrolyte ( $\mathrm{StSO}_{3} \mathrm{Na}-\mathrm{MA}$ copolymer) depend on the inorganic component concentration. The boundwater from the dried hybrids with different silver

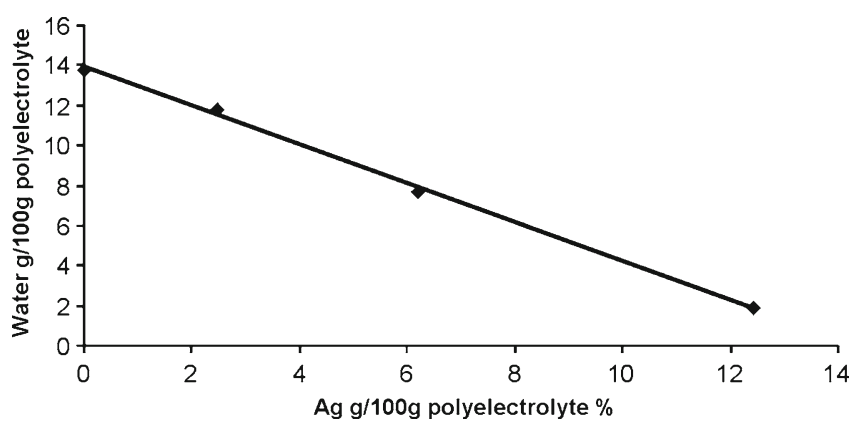

Figure 4. Amount of the bonded water present in the dried hybrids (copolymers $\left.\left(\mathrm{StSO}_{3} \mathrm{Na}-\mathrm{MA}\right)\right)$ at different silver NPs/polyelectrolyte ratios (calculations from TGA curves until $\left.150^{\circ} \mathrm{C}\right)$.
NPs/polyelectrolyte ratios was analysed through TGA measurements (figure 4). The weight loss measured in the range $0-150^{\circ} \mathrm{C}$ corresponds to the bound-water and decrease linearly with the silver NPs concentration. Note: The values from figure 4 were calculated for $100 \mathrm{~g}$ of polyelectrolyte in order to be compared for each analysed hybrid.

Contrary to the data published for silver NPs polyvinyl alcohol hybrids, ${ }^{2}$ the results confirm the interaction between the polyelectrolyte and silver nanoparticles. For the hybrids obtained in the polyvinyl alcohol presence, the water bound to the polymer did not depend on the concentration of the silver NPs from the system, due to the weak interactions between the non-ionic polymer and the metallic component.

\subsection{UV-Vis measurements}

Figure 5 presents the UV-Vis absorption spectra of two silver NPs dispersions 10 times diluted (samples 10,19) which prove the formation of the metallic nanoparticles. The position and shape of the plasmon absorbtion of silver particles are strongly dependent on the particle size, dielectric constant of the medium and surface adsorbed species. ${ }^{3,5,6,8-13,20,22,27}$ Both polyelectrolytes have absorption in visible region around $400 \mathrm{~nm}$ (figure 1). In case of sample 10 the $\lambda_{\max }$ at $415 \mathrm{~nm}$ indicating the formation of $\mathrm{Ag}^{0}$ and also the red shift in the maximum of plasmon peak were observed. This indicates a decrease in the size of the metallic particles with the average number of reducing agent per micelle. This is due to the increase in the protecting effect of surfactant molecules on the crystallite growth. ${ }^{21}$

In the case of sample 19 the plasmon band position is blue shifted. An explanation for this effect is that initially the particle surface is positively charged due to the unreacted $\mathrm{Ag}^{+}$and after $\mathrm{Ag}^{0}$ forming the

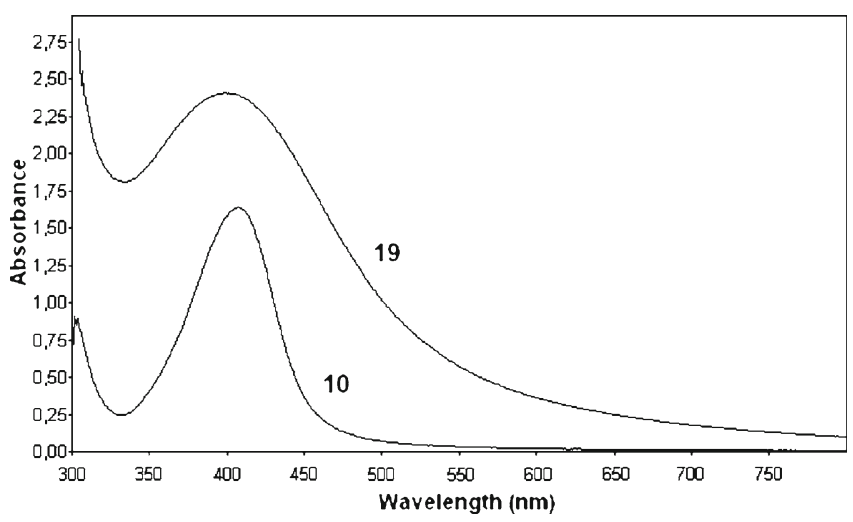

Figure 5. UV-Vis absorption of silver NPs aqueous solutions stabilized: (10) by VAc-MA and (19) by $\mathrm{StSO}_{3} \mathrm{Na}-\mathrm{MA}$ copolymers. 


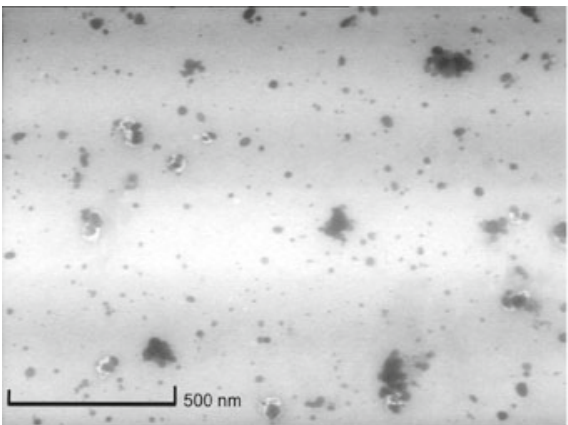

(a)

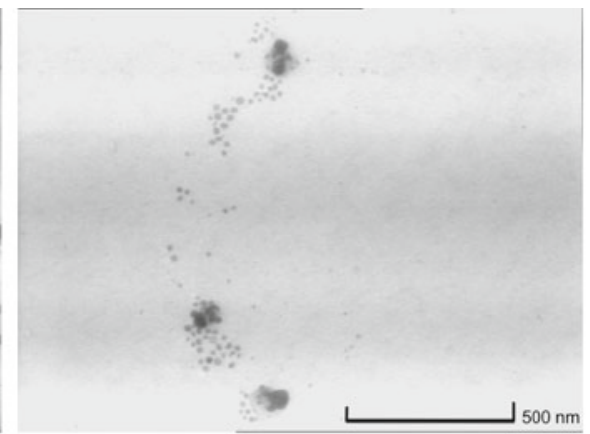

(b)

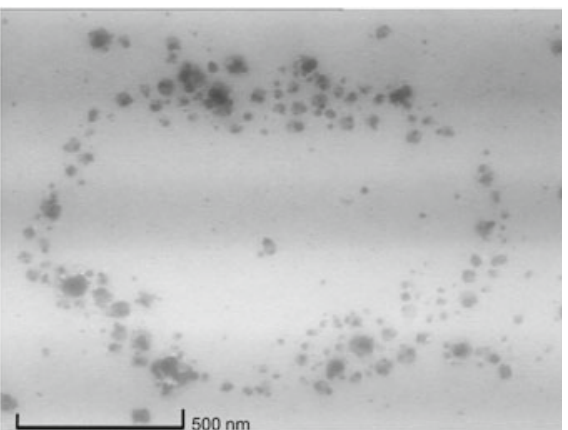

(c)

Figure 6. Transmission electron micrographs of silver NPs for samples 14 (a), 16 (b) and 19 (c).

particle surface became negative (results from Zeta potential measurement from figure 2). ${ }^{28}$

The decrease in particle diameter due to the addition of surfactant is tentatively attributed to the adsorption of the surfactant on the surface of the silver particles during the course of the reaction for both copolymers, at the maximum concentration of $\mathrm{AgNO}_{3}$.

\subsection{TEM images}

TEM images of a few representative samples $(14,16$ and 19) (figure 6) show the silver NPs formation, most of them aggregates with a spherical shape and polydisperse sizes.

Morphological information on silver nanoparticles has been obtained from HR-TEM microphotographs of the sample 16 (figure $7 \mathrm{a}$ and $\mathrm{b}$ ). ${ }^{29-31}$ The measurements were performed on undiluted samples, which contain elementary particles with higher particles dimensions, also measured by DLS (156 nm, figure 1$)$. The well-dispersed nanoparticles were observed in the wide area of the photograph and the formation of aggregated silver nanoparticles was noticed for sulphonated derivative used in the previous work ${ }^{22}$ as for other water soluble polymers. ${ }^{12}$

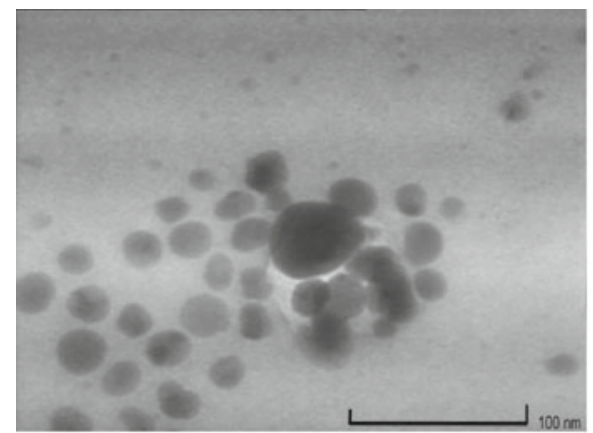

(a)

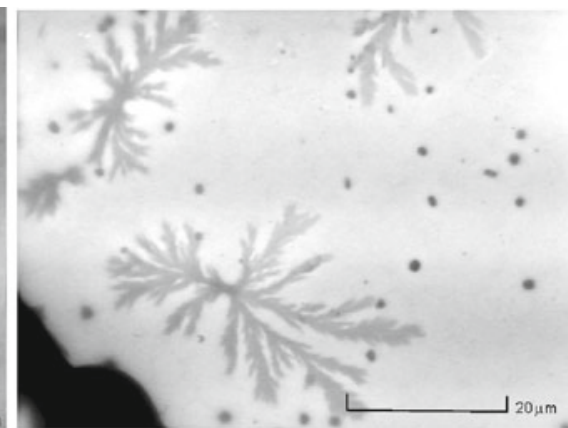

(b)

\subsection{ESEM photographs}

Another interesting fact was revealed by the HRTEM image (figure 7b): the dried polyelectrolyte (found in excess) may form aggregates with a leaf-like structure.

SEM images (after drying) of the initial aqueous solutions of $\mathrm{StSO}_{3} \mathrm{Na}-\mathrm{MA}$ copolymer $(6 \mathrm{~g}, 0.6 \mathrm{~g}$ and $0.06 \mathrm{~g}$ of copolymer in $60 \mathrm{~g}$ of water) are shown in figure 8 . In this case, the leaf-like structures are highly revealed at the lowest concentration of copolymer (figure 8a). For the maximum concentration of the polyelectrolyte (figure 8c) the micrograph shows the formation of a film with few small regions of ordered structures. ${ }^{32,33}$ The ordered structures appear in a higher percentage in the polyelectrolyte solution with $0,6 \mathrm{~g}$ copolymer (figure 8b).

A similar behaviour was noticed after drying of the hybrid samples (which contain silver NPs) (figure 9). ${ }^{33}$ For example, the sample with the highest concentration of polyelectrolyte and silver NPs (sample 19 undiluted - figure 9a), presents a similar morphology with the dried initial solution of polyelectrolyte (at the same concentration) (figure 8c), which has lower sizes for the

Figure 7. Transmission electron micrographs of silver NPs on sample (16) crystallized $\mathrm{StSO}_{3} \mathrm{Na}-\mathrm{MA}$ copolymer. 


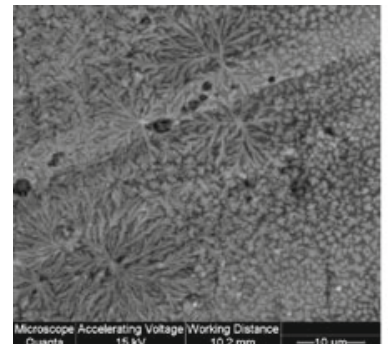

(a)

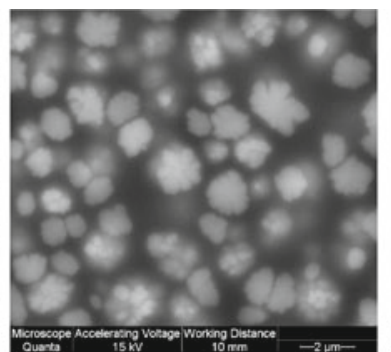

(b)

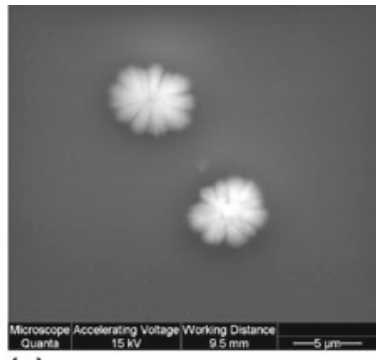

(c)

Figure 8. SEM images of the dried initial aqueous solutions of $\mathrm{StSO}_{3} \mathrm{Na}-\mathrm{MA}$ copolymer (at three concentrations: (a) $0.1 \%$; (b) $1 \%$ and (c) $10 \%$ ).

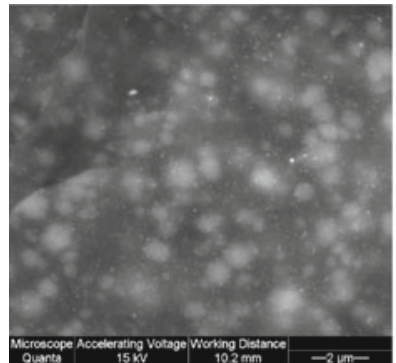

(a)

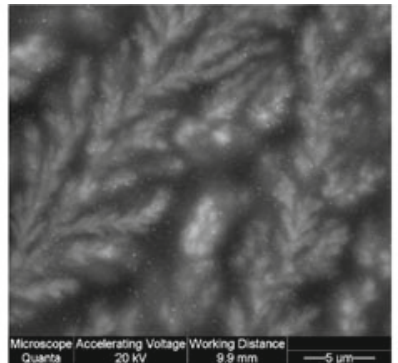

(b)

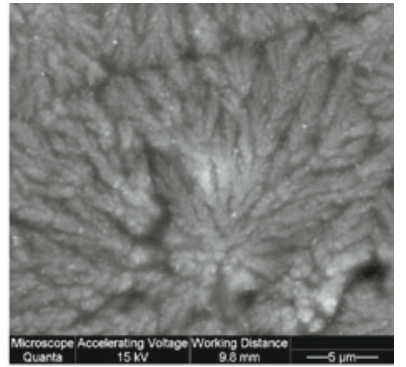

(c)

Figure 9. SEM images of hybrid samples (which contain silver NPs) stabilized by $\mathrm{StSO}_{3} \mathrm{Na}-\mathrm{MA}$ copolymer, after drying (19 undiluted (a), 19 diluted 10 times (b) and 17 undiluted (c)).

ordered structures. The same sample, 10 times diluted and then dried (figure 9b) presents leaf-like associations, like the initial solution of polyelectrolyte at the same concentration (figure 8a). Sample 17 has also a leaf-like structure (figure 9c) like sample 19 (diluted). Sample 17 has the concentration of the silver NPs four times higher than the polyelectrolyte concentration. The higher concentration of the metallic particles implies strong interactions of silver NPs with the polymer.

Hence, SEM images suggest the existence of strong interactions between the polyelectrolyte macromolecules and silver NPs in solid state. The two components of the hybrids are separated only at very high dilutions, prepared especially for TEM measurements (figure $7 b$ ).

The solid hybrids resulting after water evaporation of VAc-MA copolymer solutions (figure 10) have different morphologies like the $\mathrm{StSO}_{3} \mathrm{Na}-\mathrm{MA}$ copolymer hybrids. Samples 19 ( $\left.\mathrm{StSO}_{3} \mathrm{Na}-\mathrm{MA}\right)$ and 7 (VAc-MA) were synthesized in the same conditions. Unlike $\mathrm{StSO}_{3} \mathrm{Na}-\mathrm{MA}$ copolymer, VAc-MA copolymer led to the formation of very thin films (figure 10a). The morphology of the sample 10 times diluted does not show the leaf-like associations (figure 10b).
Sample 5 (hybrid obtained from polyelectrolytes solutions of VAc-MA) (figure 10c) has a different morphology from the sample 17 (hybrid obtained from polyelectrolytes solutions of $\mathrm{StSO}_{3} \mathrm{Na}-\mathrm{MA}$ copolymers) (figure 9c). The VAc-MA copolymer forms a film (undiluted sample) without leaf-like associations but with higher concentration of metallic NPs.

Thus, SEM images from figures 9 and 10 present different morphologies of the dried hybrids.

\subsection{Antifungal and antibacterial tests}

Further are shown the results from the tests regarding the antifungal and antibacterial activities for a few samples synthesized only with $\mathrm{StSO}_{3} \mathrm{Na}-\mathrm{MA}$. For these tests, only sample with $\mathrm{StSO}_{3} \mathrm{Na}-\mathrm{MA}$ copolymer due to their better stability in time were chosen.

3.8a Antifungal tests: The antifungal activity of the silver NPs solutions was tested against the following fungi: Aspergillus niger, Aspergillus fumigatus, Aspergillus flavus, Aspergillus terreus, Chaetomium globosum, Myrothecium verrucaria, Paecilomyces varioti, Penicillium glaucum, Penicillium cyclopium, 


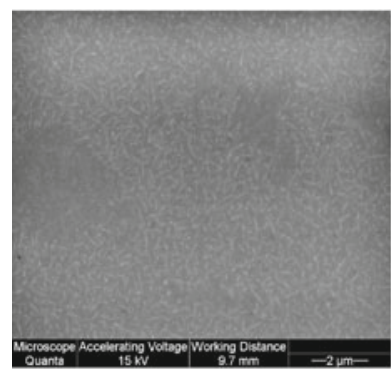

(a)

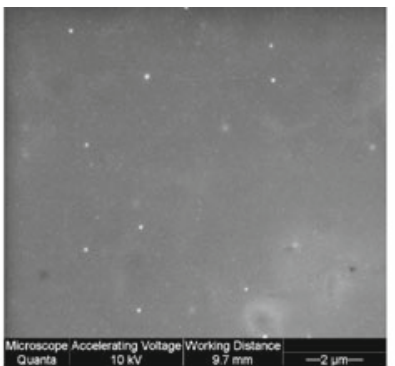

(b)

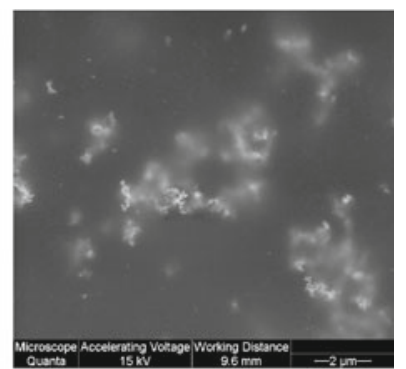

(c)

Figure 10. SEM images of hybrid samples (which contain silver NPs) stabilized by VAc-MA copolymer, after drying (7 undiluted (a), 7 diluted 10 times (b) and 5 undiluted (c)).

Table 2. The antifungal activity of samples stabilized by $\mathrm{StSO}_{3} \mathrm{Na}-\mathrm{MA}$ copolymer.

\begin{tabular}{|c|c|c|c|c|}
\hline \multirow{3}{*}{$\begin{array}{l}\text { Sample } \\
\text { code }\end{array}$} & \multicolumn{4}{|c|}{ Exposure time of test sample } \\
\hline & 3 days & 7 days & 14 days & 28 days \\
\hline & \multicolumn{4}{|c|}{ Growth rating, growing germs around the inhibition area and the size of the inhibition area, $\mathrm{mm}$} \\
\hline 14 & $\begin{array}{l}\text { Without inhibition area } \\
\text { and mould growths }\end{array}$ & $\begin{array}{l}\text { Without inhibition area } \\
\text { and mould growths }\end{array}$ & $\begin{array}{l}\text { Without inhibition area } \\
\text { and mould growths }\end{array}$ & $\begin{array}{l}\text { Without inhibition area } \\
\text { and mould growths }\end{array}$ \\
\hline 16 & $\begin{array}{l}\text { Without inhibition } \\
\text { area }\end{array}$ & $\begin{array}{l}\text { Without inhibition area } \\
\text { and very weak grouth of } \\
\text { Trichoderma viride }\end{array}$ & $\begin{array}{l}\text { Without inhibition } \\
\text { area and grouth of } \\
\text { Trichoderma viride }\end{array}$ & $\begin{array}{l}\text { Without inhibition } \\
\text { area and grouth of } \\
\text { Trichoderma viride }\end{array}$ \\
\hline 17 & $\begin{array}{l}1 \mathrm{~mm} \text { inhibition area, but } \\
\text { weak mould growths }\end{array}$ & $\begin{array}{l}1 \mathrm{~mm} \text { inhibition area, but } \\
\text { very weak growths of } \\
\text { Trichoderma viride }\end{array}$ & $\begin{array}{l}1 \mathrm{~mm} \text { inhibition area, } \\
\text { partial covered with } \\
\text { Trichoderma viride }\end{array}$ & $\begin{array}{l}1 \mathrm{~mm} \text { inhibition area, } \\
\text { partial covered with } \\
\text { Trichoderma viride }\end{array}$ \\
\hline 19 & Full inhibition & $\begin{array}{l}\text { Full inhibition, but weak } \\
\text { growths of Penicillium } \\
\text { species on the sample }\end{array}$ & $\begin{array}{l}2-3 \mathrm{~mm} \text { clear inhibition } \\
\text { area and Penicillium } \\
\text { species on the rest of } \\
\text { the sample }\end{array}$ & $\begin{array}{l}\text { 2-3 mm constant inhibition } \\
\text { area, but slightly covered } \\
\text { with Aspergillus flavus and } \\
\text { Penicillium species on the } \\
\text { rest of the sample }\end{array}$ \\
\hline
\end{tabular}

Stachybotris atra, Trichoderma viride and Scopulariopsis brevicaulis. There were distinct differences among them. When Ag nanoparticles were tested in Aspergillus niger, fumigatus and terreus, Chaetomium globosum, Myrothecium verrucaria, Paecilomyces varioti, Stachybotris atra and Scopulariopsis brevicaulis, they had no inhibition area or mould growths. Ag nanoparticles showed antifungal activity only against Aspergillus flavus, Trichoderma viride and Penicillium species. The results from testing the antifungal activity for samples 14, 16, 17 and 19 are presented in table 2. As it was expected, the best results were obtained for sample 19, having a maximum concentration of silver NPs (1177 ppm) and stabilized in the solution having the highest concentration of the polyelectrolyte. After 3 days, on this sample no colonies appeared. After 7 days, very weak growth of Penicillium species appeared. After another 4 days, around the sample testing roundels there was a clear inhibition area of 2$3 \mathrm{~mm}$. The inhibition area remained constant even after 28 days of exposure, but it was slightly covered with Aspergillus flavus.

The sample 17 had a concentration of 927 ppm silver NPs. After 3 days, very weak mould growths were observed, but around the sample there was an inhibition area of $1 \mathrm{~mm}$. After 7 days, the inhibition area was preserved, but insignificant growth of Trichoderma viride appeared on the sample. After 14 days, (28 days from the inoculation) the inhibition area remained constant, but it was partially covered with Trichoderma viride.

In spite of having the same concentration of silver NPs (927 ppm), samples 16 and 17 exhibited different antifungal properties. This proves that the concentration 
Table 3. The minimal inhibitory concentrations (MIC) of some samples stabilized by $\mathrm{StSO}_{3} \mathrm{Na}-\mathrm{MA}$ copolymer.

\begin{tabular}{lcccccc}
\hline \multicolumn{5}{c}{ Tested germs/minimal inhibitory concentration (MIC), ppm } \\
\cline { 2 - 7 } $\begin{array}{l}\text { Sample } \\
\text { code }\end{array}$ & $\begin{array}{c}\text { Staphilococus } \\
\text { aureus }\end{array}$ & $\begin{array}{c}\text { Escherichia } \\
\text { coli }^{38}\end{array}$ & $\begin{array}{c}\text { Pseudomonas } \\
\text { aeruginosa }\end{array}$ & $\begin{array}{c}\text { Klebsiella } \\
\text { pneumoniae }\end{array}$ & $\begin{array}{c}\text { Enterobacter } \\
\text { spp }\end{array}$ & $\begin{array}{c}\text { Acinetobacter } \\
\text { baumannii }\end{array}$ \\
\hline 14 & 231.5 & 231.5 & 231.5 & 231.5 & 231.5 & 231.5 \\
16 & 463.5 & 463.5 & 927 & $*$ & $*$ & $*$ \\
17 & $<115.3$ & 231.6 & $<115.3$ & 231.6 & 231.6 & $<115.3$ \\
19 & $<134.6$ & $<134.6$ & $<134.6$ & 269.2 & 269.2 & $<134.6$ \\
\hline
\end{tabular}

*Without antibacterial activity

of the stabilizing agent from the colloidal suspension has an important role.

The sample 14, that has a concentration of only 463 ppm silver NPs, did not show an inhibition area, and the mould growths were progressive until 28 days after the inoculation, covering the entire surface of the tested sample.

3.8b Antibacterial tests: The minimal inhibitory concentrations (MIC) of some samples stabilized by $\mathrm{StSO}_{3} \mathrm{Na}-\mathrm{MA}$ copolymer are shown in table 3 .

Previously studies show the attachment of antibacterial agents on the styrene-maleic anhydride copolymer (anionic copolymer). It is well-known that cationic polyelectrolyte have antibacterial activity, ${ }^{35-37}$ while the anionic polyelectrolyte (this case) does not have antibacterial activity. Starting from the known fact that $\mathrm{StSO}_{3}$-MA copolymer has no antibacterial activity; the purpose of this study was to prove that in the presence of $\mathrm{AgNO}_{3}$ the antibacterial activity is present (by reduction of $\mathrm{Ag}^{+}$ions to $\mathrm{Ag}^{0}$ ).

The results obtained by testing the antibacterial activity of Gram positive and negative bacteria: Staphiloccocus aureus, Escherichia coli, Pseudomonas aeruginosa, Klebsiella pneumoniae, Enterobacter spp, and Acinetobacter baumannii on the samples 14, 16, 17 and 19 are shown in table 3 . These results show a large spectrum of antibacterial activity for the colloidal solutions that were tested. The intensity of the antibacterial activity increases with the concentration of bioactive silver NPs and with concentration of $\mathrm{StSO}_{3} \mathrm{Na}-\mathrm{MA}$ copolymer in the following order: sample $16<$ sample $14<$ sample $17<$ sample 19 . These results are in good agreement with the results obtained from the antifungal assessments.

\section{Conclusions}

This paper focused on obtaining ecological biocide solutions with high stability and antifungal/antibacterial properties, based on silver NPs. Two types of dispersions were synthesized by reduction of $\mathrm{Ag}^{+}$ions with glucose in the presence of two polyelectrolyte stabilizers: aqueous solutions of maleic anhydride with vinyl acetate (VAc-MA) and with styrene sulphonic acid sodium salt ( $\left.\mathrm{StSO}_{3} \mathrm{Na}-\mathrm{MA}\right)$ copolymers.

The solid hybrids obtained by water evaporation in air of the silver NPs-alternant copolymer dispersions were characterized by analysing the morphology and the interactions between silver NPs and the polyelectrolytes, through analyses of the average diameters, the shape, the $\mathrm{pH}$, the stability and the absorbance in UVVis. The dry products obtained by water evaporation can form stable dispersions simply by adding water. This proves that interactions between the polyelectrolyte and the silver NPs occur. The strong interactions between the components from the aqueous solutions are evidenced by their stability. Most of the synthesized dispersions $(\sim 60 \%)$ were stable after one year, suggesting that the used preparation technique is successful for obtaining silver NPs.

The results of the antimicrobial tests proved that the activity of the dispersions with silver NPs content higher than $927 \mathrm{ppm}$.

\section{Acknowledgements}

Authors thank for the financial support received from the European Social Fund through POSDRU/ 89/1.5/S54785 project: 'Postdoctoral Program for Advanced Research in the field of nanomaterials.' The financial support from CNCSIS-UEFISCSU, postdoctoral grant PNII-RU no.44 (PD_206)/2010 is also gratefully acknowledged.

\section{References}

1. Carotenuto G 2005 Metal-polymer nanocomposites (ed) L Nicolais (Italy: Wiley Interscience)

2. Galya T, Sedlarik V, Kuritka I, Novotny R, Sedlacikova J and Saha P 2008 J. Appl. Polym. Sci. 1103178 
3. Kumar A, Vemula P K and Ajayan J P G 2008 Nat. Mater. 7236

4. Mohan Y M, Lee K, Premkumar T and Geckeler K E 2007 Polymer 48158

5. Thomas V, Yallapu M M, Sreedhar B and Bajpai S K 2007 J. Coll. Int. Sci. 315389

6. Murthy P S K, Mohan Y M, Varaprasad K, Sredhar B and Raju K M 2007 J. Coll. Int. Sci. 318217

7. Chen C, Wang L, Jiang G and Yu H 2006 Rev. Adv. Mater. Sci. 111

8. Mbhele Z H, Salemane M G, van Sittert C G C E, Nedeljkovic U and Luyt A S 2003 Chem. Mater. 155019

9. Morones J R and Frey W 2007 Langmuir 238180

10. Huang Y F, Liu Y W and Chang H T 2007 Langmuir 23 12777

11. Radziuk D, Shchukin D G, Skirtach A, Mohwald H and Sukhorov G 2007 Langmuir 234612

12. Hussain I, Brust M, Papworth A J and Cooper A I 2003 Langmuir 194831

13. Sardar R, Park J W and Shumaker-Parry J S 2007 Langmuir 2311883

14. Donescu D, Somoghi R, Purcar V, Serban S, Ghiurea M, Petcu C, Radovici C and Fierascu R 2010 JOAM 12(6) 1399

15. Chen Z, Gang T, Zhang K, Zhang J, Cheng X, Sun Z and Yang B 2006 Colloids Surfaces A: Physicochem. Eng. Aspects 272151

16. Kim J S, Kuk E, Yu K N, Kim J H, Park S J, Lee H J, Kim S H, Park Y K, Park Y H, Hwang C Y, Kim Y K, Lee Y S, Jeong D H and Cho M H 2007 Nanomed. Nanotech. Biol. Med. 395

17. Sharma V K, Yngard R A and Lin Y 2009 Adv. Colloid Interface Sci. 145(1-2) 83

18. Donescu D, Serban S and Petcu C 2001 Mat. Plast. 38133

19. Singh A K and Raykar V S 2008 Colloid Polym. Sci. 2861667

20. Petit C, Lixon P and Pileni M P 1993 J. Phys. Chem. 9712974
21. Ung T, Giersig M, Dunstan D and Mulvaney P 1997 Langmuir 131773

22. Sondi I, Goia D and Matijevic E 2003 J. Coll. Int. Sci. 26075

23. Donescu D, Serban S, Fusulan L and Petcu C 1998 J. Macromol. Sci. - Pure Apll. Chem. A 351741

24. Vijayendran B L, Bone T and Gajria C 1981 In Emulsion polymerization of vinyl acetate (eds) M S El-Aasser and J Vanderhoff (Appl. Sci. Publ.) p. 253

25. Joon K J, Woo J H and Seo Y S 2003 Fibres Polymers 4(4) 182

26. Jeon H J, Yi S C and Oh S G 2003 Biomaterials 244921

27. Heilmann A 2005 In Metal-polymer nanocomposites (eds) L Nicolais and G Carotenuto (Wiley Interscience) p. 183

28. Jin R, Cao Y W, Mirkin C A, Kelly K L, Sehatz G C and Zheng J G 2001 Science 2941901

29. Le A T, Huy P T, Tam P D, Huy T Q, Cam P D, Kudrinskiy A A and Krutyakov Y A 2010 Curr. Appl. Phys. 10910

30. Sharma V K, Yngard R A and Lin Y 2009 Advances in Colloid Interface Sci. 14583

31. Kvitek L, Prucek L, Panacek A, Soukupova J and Vanickova M 2009 NANOCON, Conference Proceedings 74-82

32. Donescu D, Nistor C L, Purcar V, Serban S, Radovici C, Raditoiu V, Petcu C and Ghiurea M 2009 J. Nano Res. 6 147

33. Purcar V, Donescu D, Ghiurea M, Nistor C L and Petcu C 2007 Rev. Roumaine Chim. 52(8-9) 917

34. Gavriliu S, Lungu M and Ciobanu C 2006 Electrotehnica, Electronica, Automatica 54(1) 23

35. Grosso M H 1998 US Patent no. 5759799. 2

36. Thompson G A and Watling R J 1983 J. Bull. Environ. Contam. Toxicol. 31705

37. Shurrab M Y 2006 J. Contemp. Dental Practice 7(4) 1

38. Janardhanan R, Karuppaiah M, Hebalkar N and Rao T 2009 Polyhedron 282522 